\title{
Impact of industry experience on faculty teaching practices in STEM
}

\author{
Dehui $\mathrm{Hu}$ and Benjamin M Zwickl \\ School of Physics and Astronomy, Rochester Institute of Technology, 84 Lomb Memorial Drive, Rochester, NY 14623 \\ Carmen Carusone \\ Department of Physics, The College of New Jersey, 2000 Pennington Rd, Ewing, NJ 08618
}

As part of a larger study of how problem-solving, communication, and teamwork are integrated into STEM education, we examined how industrial work experience impacts faculty teaching practices around those same competencies. We conducted semi-structured individual interviews with 92 educators in four broad fields, including energy, healthcare, computing, and advanced manufacturing. Educators' industrial experience ranged from no prior experience to a decade or more of industrial experience, which largely depends on STEM field. This paper will report findings from preliminary analysis with six educator interviews in energy and advanced manufacturing. Industry work experience greatly influenced educators' perceptions of the competencies as well as teaching strategies. Instructors with rich industry experience often include more descriptive examples of industrial applications when defining those skills, use industrial-specific tasks to inspire the design of classroom activities, and utilize their industry work experience to help formulate course structure.

2019 PERC Proceedings edited by Cao, Wolf, and Bennett; Peer-reviewed, doi.org/10.1119/perc.2019.pr.Hu Published by the American Association of Physics Teachers under a Creative Commons Attribution 4.0 license. Further distribution must maintain attribution to the article's authors, cover page, and DOI. 


\section{INTRODUCTION}

Due to the rapid change of technology and the nature of work in the 21st century, it is critical for physics and other STEM programs to provide students with cognitive skills, such as problem-solving [1]. However, transferable noncognitive skills (i.e., personality traits that are weakly correlated with measures of intelligence [2,3]), interpersonal skills (e.g., communication and teamwork), and self-directed learning are of equal, and perhaps greater, importance for success in school and the workplace [3-5]. This combination of both cognitive, non-cognitive, and interpersonal skills, often called "21st century competencies" are crucial for STEM professionals in workplace $[1,6]$.

Programs designed to prepare STEM teachers at the K12 level (e.g., PhysTEC conferences [7]) as well as higher education (e.g., the Center for the Integration of Research, Teaching, and Learning [8]) focus on introducing faculty to active learning methods and educational resources backed by extensive STEM-education research, however, they do not offer strategies for preparing students to enter industry or include industry experience as part of faculty professional development. Furthermore, the new physics and astronomy faculty Workshop primarily target at introducing new faculty to research-based teaching methods and resources (e.g., University of Washington tutorials and PhET simulations) to improve student understanding and enhance active learning [9-11]. Literature on disciplinary-based education research and faculty development research have discussed strategies and developed models to facilitate change in undergraduate STEM education, however, little research was done to study the influence of industry experience on faculty teaching practice $[12,13]$. One main focus of this study is to understand the impact of industrial experience on educators' teaching around 21 st century competencies.

\section{METHODOLOGY}

\section{A. Research design}

We conducted one-on-one semi-structured interviews with 92 educators in the photonics, information technology, energy, and advanced manufacturing industries across four high STEM regions. Each educator interview is approximately 30-60 minutes long. The educator protocol included questions about: (a) the personal and professional background of each respondent, (b) definitions of the four targeted competences (problem-solving, teamwork, communication, and self-direted learning), (c) the degree to which the four targeted competencies are explicitly incorporated into the respondent's course design and teaching practices, (d) whether active learning techniques are used for teaching these competencies, (e) types of relations respondents and their programs have with industry, and (f) the factors that support or inhibit the focus on these competencies and the use of active learning techniques to teach these competencies. All interviews were audio-taped and transcribed for analysis.

\section{B. Data analysis}

The interview transcripts were imported into QSR International's NVivo 12 qualitative data analysis software for a detailed qualitative analysis. In this paper we present an analysis of six interviews with educators who currently teach undergraduate level courses. Two other main factors affected our selection of educator interviews: first, we tried to keep equal numbers of educators with and without industry experience; secondly, we intentionally selected three educators with 20 years or more of industry experience and the other three without any industry experience. Educators' demographic information is shown in Table I.

The qualitative data analysis took several steps. The first step was an open coding process with the purpose of finding instances about how instructors define 21 st century skills, value those skills, and implement strategies to teach those skills, especially instances that they refer to their prior industry experience, learning or teaching experience in school. The authors (first and last authors) first coded one interview together and assigned descriptive open codes to quotes selected. Then each coder coded the other five interviews separately. The second step was to compare the instances selected and make sure all instances that are related to the research questions were included. The third step was to categorize the codes to three groups: defining skills, value of skills, and implementing strategies. Each coder grouped the codes separately and summarized the major themes. Lastly, the two coders discussed the major themes together and resolved any disagreement.

\section{RESULTS}

We grouped the results into three major themes. For each theme, we have given an overview of the main trends and support those trends with quotes.

\section{A. Defining skills: Descriptive examples from industry vs Brief definition with classroom examples}

When defining the four targeted competencies (i.e., communication, problem-solving, teamwork, and self-directed learning), one striking difference is that instructors with industry experience often provided more descriptive and specific definitions of skills, which are often contextualized in a variety of industrial settings; whereas instructors without industry experience mostly provided a brief definition, occasionally supplemented with examples from classroom context. Instructors who have worked in industry for many years often recalled their industry work experience and included 
TABLE I. Demographic information of educators

\begin{tabular}{|c|c|c|c|c|c|c|}
\hline $\begin{array}{l}\text { Instructor } \\
\text { Code }\end{array}$ & NI-1 & IE-1 & NI-2 & NI-3 & IE-2 & IE-3 \\
\hline Discipline & $\begin{array}{l}\text { Electrical \& Com- } \\
\text { puter Engineering }\end{array}$ & $\begin{array}{l}\text { Electrical \& Com- } \\
\text { puter Engineering }\end{array}$ & Physical Science & Physical Science & $\begin{array}{l}\text { Petroleum Engi- } \\
\text { neering }\end{array}$ & $\begin{array}{l}\begin{array}{l}\text { Petroleum } \\
\text { neering }\end{array} \\
\text { Engi- }\end{array}$ \\
\hline $\begin{array}{l}\# \text { of years in } \\
\text { teaching }\end{array}$ & 35 years & 20 years & 29 years & 6 years & 0.5 year & 5 years \\
\hline
\end{tabular}

very descriptive examples of how those skills are applied in industry situations. However, instructors who never worked in industry before usually recalled their experience as a student or teacher to help explain what those skills are.

Instructor IE-2 with 30+ years of industry experience teaches a junior-level class in petroleum engineering, described what different types of communication look like in the petroleum industry: one is presenting ideas or results to team members or upper management, and the other is informal interpersonal communication with colleagues.

"I think communication the first one clearly is presentation in any kind of setting. I think most of the work at least that I'm experienced with in the upstream business of petroleum, every project you do have to present you know either through your own team members or to upper management... The second one of course is interpersonal relate-communication, I mean you do have to interact you need to face your colleagues in that you know. Usually it's not very formal, usually it's you go in and then you know request some data..."

Then he continued to describe communication in a larger scale, that is to establish a network within the community, which he perceived as a more important communication skill.

\begin{abstract}
"But I would say probably most important one... it's a really small community... So, the participation in the petroleum engineering society is very critical... to start meeting people able to go into any kind of event and they go to communicate and chat or talk...it's a great opportunity for you to meet and to establish a network... So that, be another communication skill, yeah."
\end{abstract}

In contrast to the detailed and descriptive definitions from instructors who have worked in industry for many years, instructors with no prior industry experience often gave short definitions and might have recalled a classroom setting involving one of those skills.
Instructor NI-1 without industry experience teaches a large undergraduate class in Electrical and Computer Engineering. He defined problem-solving from the perspective of classroom problem-solving and communication as instruction-student question-answer type of interaction in classroom teaching.

"Problem-solving comes from their being able
to apply the mathematical tools that they've
learned in class. And I often will ask them ques-
tions and give them time to answer the question.
And then somebody usually raises their hand,
and I call on them to answer the question that
I posed. Communication."

B. Value of skills: Both skills are valued vs cognitive skills are valued more

Throughout the interview, instructors often expressed their opinions about the importance of certain skills that students need to acquire from the program. Some of those are more technical or cognitive skills related to problem-solving, including modeling, programming, mechanical and mathematical skills, while others are interpersonal skills including communication and teamwork skills. A general trend across the two groups of instructors with and without industry experience is that instructors with many years of industry experience seem to have valued both technical expertise and soft skills like teamwork and communication, and often put even more emphasis on teamwork and communication skills in class when possible. However, instructors without industry experience seemed to focus more on cognitive skills (e.g., conceptual understanding, modeling, and problem-solving) in class.

Instructor IE-3 with 20+ years of industry experience currently teaches a laboratory-based undergraduate course in a petroleum engineering department. His students worked collaboratively in a classroom structure that fostered teamwork (as described in the next section). To him, teamwork is one of the most important skills that students need for their future work in industry. In his class, he always specifically 
told students the importance of teamwork in industry during his teaching and motivated students to learn from working as a team when there are conflicts within teams.

"I always try to tell them, in the company you have to do teamwork. You are not truly a boss of a team, the truth is, your boss assign you to a team. If you do not do the teamwork, you can not like, 'I don't like this team'..."

Instructor IE-1 has worked in the computing industry for 30+ years and currently teaches an undergraduate programming class. His experience told him cognitive skills are definitely critical for a beginning programmer. While communication skills are not specifically required for a new hire, good communication skills will support long-term success in the company.

\section{"That's [communication] not the big require- ment of a new programmer... As they are around longer, it turns out that somebody has to explain what this group of programmers is doing to the management team or the sales team or the cus- tomer team that are not so technical...This turns out to be a very important skill.}

Instructor NI-2 with no industry experience but 29 years of teaching experience teaches a freshman physical science course. He believed problem-solving skills will give the foundation for students to go into any speciality in the future.

"When students ask me, I try to emphasize that there's a huge amount of different directions you can go with a physics degree because it's really a degree in problem-solving."

Then he continued to add that the goal of the undergraduate courses in his program is to prepare students for graduate school, not nonacademic jobs.

"I think the truth is most of our faculty... they're really designing this course to get the undergrads into grad school, and they don't give a lot of thought to preparing them for nonacademic jobs where things like teamwork and communication are essential. You can be a lousy communicator and survive in academia... but I don't think you'd get very far in industry if you're a lousy communicator..."

Instructor NI-3 without industry experience teaches a junior-level computation course in physical science. He discussed the use of tutorial activities in his class as a means to encourage, but not require teamwork. However, he emphasized that the primary purpose of tutorials was to practice students' problem-solving skills.

"So communication and teamwork, it's not really part of the formal structure of the course I would say. So I informally encourage it in a few ways. So, on the tutorials, they are encouraged, but not required to talk to their neighbors... So the same is true on the homework. I encourage them to work together in small groups."

C. Implementation strategies: practices inspired by industrial experience vs personal experience

Industry experience also impacted an instructor's implementation strategies. They made efforts to integrate both cognitive and soft skills like communication and teamwork. They intentionally linked the course content to industrial professional practices to increase student interest of learning, and arranged the class in a way that mimics the team environment in industry. Instructors without industry experience focused on developing cognitive skills useful for graduate school and research, while teamwork and communication skills were informally supported through active learning strategies.

Beyond the many differences, all instructors attempted to help students prioritize building higher-level critical thinking skills (such as qualitative analysis and developing physical intuition) rather than getting results. Although instructors with years of industry work experience strongly emphasized the importance of teamwork and communication skills, some of them have trouble with integrating those competencies into their classroom teaching due to large class size, and the focus of current curriculum (e.g., teaching communication in an advanced course instead of freshman or junior-level course).

Instructor IE-1 with 30 years of industry experience teaches a junior-level course in electrical and computer engineering took time out of class to link the course content to future industry work and made students aware of the application of knowledge in industry.

"At the beginning of the course, tell them, 'I will talk about [how things work and why things work]... because that's what you're going to be doing when you get out.' ... but then you start designing what you're doing and maybe what others are doing. And so you've got to be able to have some feeling for the why and how."

He also mentioned that a lab project he designed was inspired by a project he did in a company years ago.

\footnotetext{
"I totally changed this course... because I added my feelings about what you need to know when you get out in the industry, all right? And secondly, things are changing very rapidly in this technology... we weren't doing artificial intelligence 10 years ago. We have a lab where we're doing artificial intelligence this semester where they've written [a] program that makes the user think they're doctor... and IBM wrote a thing like this 30 years ago..."
} 
Instructor IE-3 with 20+ years of industry experience structured his class in a way that it specifically integrates teamwork and communication skills while students are working on labs. He taught teamwork by assigning them to structured teams during labs. He taught communication by letting students deal with friction within a team and writing coauthored professional lab reports.

"In the lab we always practice in groups in teams, like every lab they are assigned to different roles, one is team leader, other team member is assigned to do some other things, and then they do the lab together and they come home to practice a report like this, written by team. They have to co-author it and well [a] problem [is] like a team member complains to each other, like do not agree to each other, it's a process of learning."

"It's just like if you work in the company. Most of the team, they called it the multi-discipline team, and most of the report is cross the majors. The team you have ten different majors, everyone works on their own part. And also one person is output maybe is other person's input."

Instructor NI-2 with no industry experience was asked to explain his teaching methods in class, and he discussed the use of both traditional lectures and active learning strategies (predominantly clicker questions and tutorials) to enhance interactive engagement.

"The only interactive engagement I have is clicker questions and peer instruction. So I will have between 5 and 10 clicker questions, and I try and use the blackboard sparingly."

Instructor NI-1 without industry experience was asked to explain what influenced his teaching approach, and he explained that the predominant influences to his teaching style were his experiences as a student and as a teacher.

\section{"[Teaching approaches are] developed through experience. The department generally doesn't offer many opportunities for learning teaching methods. It's pretty much up to the individual to go out and seek that for themselves."}

Some instructors reported regularly attending professional development workshops or interaction with other faculty members, while others reported that they received little to no assistance from their department in terms of professional development for teaching strategies.

\section{CONCLUSIONS}

This study examined the impact of industrial experience on instructor' views of 21 st century competencies and strategies for teaching those competencies. A qualitative analysis of six educator interviews showed that industrial work experience informs their perceptions of these competencies and they appear to have a richer understanding of, and place higher value on, teamwork and communication skills.

Industrial experience also inspires teaching strategies around these competencies, such as linking the course content to professional practices in industry to motivate students' learning. The study suggests that industry experience should be added as a factor when studying teacher decision-making and instructional design, and that there may be value in providing teachers at all levels with some amount of professional work experience outside of an educational institution.

In terms of implications for teaching practices, if an instructor does seek to help their students, one option is to explicitly value communication and teamwork, not merely as a means to learn physics, but as intrinsically valuable on its own. Additionally, including career-relevant examples could be done by talking to alumni, or inviting them back to campus. Project-based learning is another excellent idea for integrating open-ended problem-solving, collaboration, and meaningful applications.

The most significant limitation of this work was the focus on a small number of interviews. Future work will integrate all educator interviews across all four STEM fields and explore emergent themes related to their teaching practices around those competencies.

\section{ACKNOWLEDGMENTS}

This work is supported by NSF Award DGE-1561493. The study design and data collection was done in conjunction with Matt Hora, Ross Benbow, Bailey Smolarek and other collaborators at the Wisconsin Center for Education Research. 
[1] N. R. Council et al., Education for life and work: Developing transferable knowledge and skills in the 21st century (National Academies Press, 2013).

[2] E. K. Nyhus and E. Pons, Journal of Economic Psychology 26, 363 (2005).

[3] G. Brunello and M. Schlotter, (2011).

[4] J. J. Heckman, J. Stixrud, and S. Urzua, Journal of Labor economics 24, 411 (2006).

[5] J. Pellegrino and M. Hilton, Washington, DC: National Research Council (2012)

[6] K. Howells, (2018).

[7] N. APS, AAPT, "Phystec2019 conference schedule," (2019).

[8] N. University of Wisconsin, "Center for the integration of research, teaching and learning," (2003-2019).
[9] C. Henderson, American Journal of Physics 76, 179 (2008).

[10] C. Henderson, M. Dancy, and M. Niewiadomska-Bugaj, Physical Review Special Topics-Physics Education Research 8, 020104 (2012).

[11] A. A. of Physics Teachers, "New physics and astronomy faculty workshop," (2019).

[12] A. L. Beach, C. Henderson, and N. Finkelstein, Change: The Magazine of Higher Learning 44, 52 (2012).

[13] M. Dancy and C. Henderson, American Journal of Physics 78, 1056 (2010). 